Keywords: castration-resistant prostate cancer; prednisolone; glucocorticoid receptor; steroid switch; abiraterone; hormone therapy; dexamethasone; androgen receptor

\title{
Tumour responses following a steroid switch from prednisone to dexamethasone in castration-resistant prostate cancer patients progressing on abiraterone
}

D Lorente ${ }^{1}$, A Omlin ${ }^{1,2}$, R Ferraldeschi ${ }^{1}$, C Pezaro ${ }^{1}$, R Perez ${ }^{1}, \mathrm{~J} \mathrm{Mateo}^{1}$, A Altavilla ${ }^{1}, \mathrm{Z}$ Zafeirou ${ }^{1}, \mathrm{~N}$ Tunariu ${ }^{1}$, C Parker ${ }^{3}$, D Dearnaley ${ }^{3}$, S Gillessen ${ }^{2}$, J de Bono ${ }^{*}, 1$ and G Attard ${ }^{1}$

${ }^{1}$ Prostate Cancer Targeted Therapy Group and Drug Development Unit, The Royal Marsden NHS Foundation Trust and The Institute of Cancer Research, Downs Road, Sutton SM2 5PT, Surrey, UK; ${ }^{2}$ Kantonsspital St. Gallen, Department of Oncology and Haematology, Rorschacherstrasse 95, CH-9007 St. Gallen, Switzerland and ${ }^{3}$ Academic Urology Unit, The Royal Marsden NHS Foundation Trust, Downs Road, Sutton SM2 5PT, Surrey, UK

Background: Abiraterone is a CYP17A1 inhibitor that improves survival in castration-resistant prostate cancer (CRPC). Abiraterone is licensed in combination with prednisone $5 \mathrm{mg}$ twice daily to prevent a syndrome of secondary mineralocorticoid excess. We hypothesised that a 'steroid switch' from prednisone to dexamethasone would induce secondary responses in patients progressing on abiraterone and prednisone $5 \mathrm{mg}$ b.i.d.

Methods: We performed a 'steroid switch' in patients with CRPC at PSA progression on abiraterone and prednisolone. Patients were monitored for secondary declines in PSA, radiological tumour regression and toxicity.

Results: A retrospective analysis of 30 CRPC patients who underwent a steroid switch from prednisolone to dexamethasone while on abiraterone was performed. A total of six patients (20\%) had a $\geqslant 50 \%$ PSA decline that was confirmed by a second PSA level at least 3 weeks later. In all, 11 patients (39.2\%) had a confirmed $\geqslant 30 \%$ PSA decline. Median time to PSA progression on abiraterone and dexamethasone was 11.7 weeks (95\% Cl: 8.6-14.8 weeks) in the whole cohort and 27.6 weeks (95\% Cl: 14.5-40.7 weeks) in patients who achieved a confirmed 50\% PSA decline. Nine patients had RECIST evaluable disease: two of these patients had RECIST partial response, six patients had stable disease and one patient had progressive disease at the first imaging assessment. Treatment was well tolerated, with no grade 3 and grade 4 adverse events. One patient had to be reverted to prednisolone because of grade 2 hypotension.

Conclusions: Durable PSA responses occur in up to $40 \%$ of patients following a 'steroid switch' for PSA progression on abiraterone and prednisone. Studies are ongoing to elucidate the mechanisms underlying this response.

In recent years, two novel hormonal agents have received regulatory approval for the treatment of castration-resistant prostate cancer (CRPC). Both abiraterone, a CYP17A1 inhibitor that suppresses androgen and oestrogen synthesis, and enzalutamide, a potent next-generation antiandrogen, have been shown to improve overall survival in large, randomised, placebo-controlled phase III trials (de Bono et al, 2011; Scher et al, 2012). Abiraterone was evaluated in phase III trials and is licensed for administration in combination with prednisone (administered as the active metabolite prednisolone in the UK) 
Table 1. Overall clinical characteristics at steroid switch: median (range)

\begin{tabular}{|c|c|c|c|}
\hline & Overall & Responders (PSA decline $\geqslant 50 \%$ ) & Nonresponders (PSA decline $<50 \%$ ) \\
\hline N & 30 & 8 & 22 \\
\hline Age & 68.9 years & 65 years $(61-82)$ & 69.6 years $(51.2-80)$ \\
\hline \multicolumn{4}{|l|}{ ECOG PS } \\
\hline 0 & $8(26.7 \%)$ & $4(50)$ & $4(18.2)$ \\
\hline 1 & 19 (63.3\%) & $3(37.5)$ & $16(72.9)$ \\
\hline 2 & $3(10 \%)$ & $1(12.5)$ & $2(9.1)$ \\
\hline Haemoglobin $\left(\mathrm{g} \mathrm{dl}^{-1}\right)$ & $12.6(7.9-15.2)$ & $12.6(7.9-14.4)$ & $12.6(10.9-15.2)$ \\
\hline Alk Phos $\left(\mathrm{IUI}^{-1}\right)$ & $140.5(48-2238)$ & $100(53-2238)$ & $158(48-630)$ \\
\hline $\mathrm{LDH}\left(\mathrm{IUI^{-1 }}\right)$ & $172.5(107-631)$ & $214(169-546)$ & $170(107-631)$ \\
\hline Albumin $\left(\mathrm{g} \mathrm{dl}^{-1}\right)$ & $36(25-42)$ & $36(25-42)$ & $37(33-42)$ \\
\hline PSA (ng ml-1) & $199.5(9.7-2689)$ & $331.5(9.7-2689)$ & $164(11-523)$ \\
\hline \multicolumn{4}{|l|}{ Metastases } \\
\hline B only & $12(40 \%)$ & $4(50)$ & $8(36.4)$ \\
\hline $\mathrm{B}+\mathrm{LN}$ & $12(40 \%)$ & $2(25)$ & $10(45.5)$ \\
\hline$B+V$ & $1(3.3 \%)$ & $1(12.5)$ & 0 \\
\hline$B+L N+V$ & $3(10 \%)$ & 0 & $3(13.6)$ \\
\hline LN only & $2(6.6 \%)$ & $1(12.5)$ & $1(4.5)$ \\
\hline \multicolumn{4}{|l|}{ Previous bicalutamide } \\
\hline Yes & $23(76.7 \%)$ & $6(75)$ & $17(80)$ \\
\hline No & 7 (23.3\%) & $2(25)$ & $5(20)$ \\
\hline \multicolumn{4}{|l|}{ Previous Dex monotherapy } \\
\hline Yes & $9(30 \%)$ & $4(50)$ & $5(22.7)$ \\
\hline No & $21(70 \%)$ & $4(50)$ & $17(77.3)$ \\
\hline Median time on previous Dex & $6.6 \mathrm{~m}(2-55.2)$ & $10.1 \mathrm{~m}(3.5-55.2)$ & $6.6 \mathrm{~m}(2-29)$ \\
\hline \multicolumn{4}{|l|}{ Previous CT lines } \\
\hline 0 & $4(13.3 \%)$ & 0 & $4(18.2)$ \\
\hline 1 & $24(80 \%)$ & $7(87.5)$ & $17(77.3)$ \\
\hline 2 & $2(6.6 \%)$ & $1(12.5)$ & $1(4.5)$ \\
\hline Median Time on AA $+P$ & $6.36 \mathrm{~m}(2.7-28.7)$ & $6.8 \mathrm{~m} \mathrm{(4.8-28.7)}$ & $5.4 \mathrm{~m}(2.7-16.7)$ \\
\hline Median \% PSA decline on AA + $P$ & $71.5 \%$ (99\% to $+65 \%)$ & $78.2 \%(99 \%$ to $+65 \%)$ & $66.6 \%(97 \%$ to $+63 \%)$ \\
\hline
\end{tabular}

$5 \mathrm{mg}$ twice daily, to prevent a syndrome of secondary mineralocorticoid excess caused by a loss of negative feedback of adrenocorticotropic hormone (Attard et al, 2008).

We have previously reported a randomised phase II trial of dexamethasone $0.5 \mathrm{mg}$ daily $v s$ prednisolone $5 \mathrm{mg}$ b.i.d. in CRPC patients, in which the confirmed $\geqslant 50$ PSA decline rates were $31 \%$ for dexamethasone and $17 \%$ for prednisolone (Venkitaraman et al, 2013). Moreover, in our previously reported phase I/II trial of abiraterone initially administered without concomitant corticosteroids to 54 patients, the addition of dexamethasone $0.5 \mathrm{mg}$ once daily at PSA progression on abiraterone without steroids resulted in secondary PSA declines in 25\% of patients (Attard et al, 2009), regardless of prior progression on the same dose and regimen of single agent dexamethasone. We hypothesised that changing prednisolone for dexamethasone (a term we designated 'steroid switch') would be associated with tumour responses and could re-induce sensitivity to abiraterone.

\section{PATIENTS AND METHODS}

Patient characteristics. We performed a retrospective analysis of CRPC patients in whom a steroid switch from prednisolone to dexamethasone was performed between January 2011 and December 2013 at the Royal Marsden NHS Foundation Trust and the Kantonsspital St. Gallen. All patients were experiencing PSA progression according to Prostate Cancer Working Group 2
Table 2. Treatment received after discontinuation of abiraterone and dexamethasone

\begin{tabular}{|l|c|}
\hline Cabazitaxel & $9(30 \%)$ \\
\hline Docetaxel & $3(10 \%)$ \\
\hline Enzalutamide & $2(6.7 \%)$ \\
\hline Carboplatin & $1(3.3 \%)$ \\
\hline PARP inhibitor & $1(3.3 \%)$ \\
\hline Diethylstilboestrol & $1(3.3 \%)$ \\
\hline Best supportive care & $6(20 \%)$ \\
\hline
\end{tabular}

criteria (PSAWG2) (Scher et al, 2008); in addition, radiological progression was observed in three patients before switching steroids. All patients were clinically stable. IRB approval to report these data was obtained from the Committee for Clinical Research at the Royal Marsden and Ethical Committee of the Kantonsspital St Gallen. The date of cut-off was the 4th of January 2014.

A descriptive analysis of clinical characteristics, PSA declines and previous treatments was performed. Imaging assessments were performed as per local guidelines, every 3-6 months. Treatment with abiraterone and dexamethasone was discontinued at the time of clinical or radiological progression. Patients who received doses of dexamethasone $>1 \mathrm{mg}$ once daily for more than 4 weeks were excluded from the analysis.

In accordance with PSAWG2 criteria (Scher et al, 2008), a PSA decline was defined as confirmed if it presisted in a second reading at 
least 3 weeks later. PSA progression was defined as a $25 \%$ rise above the nadir, confirmed by a second reading at least 3 weeks later (Scher et al, 2008). Time to PSA progression was defined as the time from
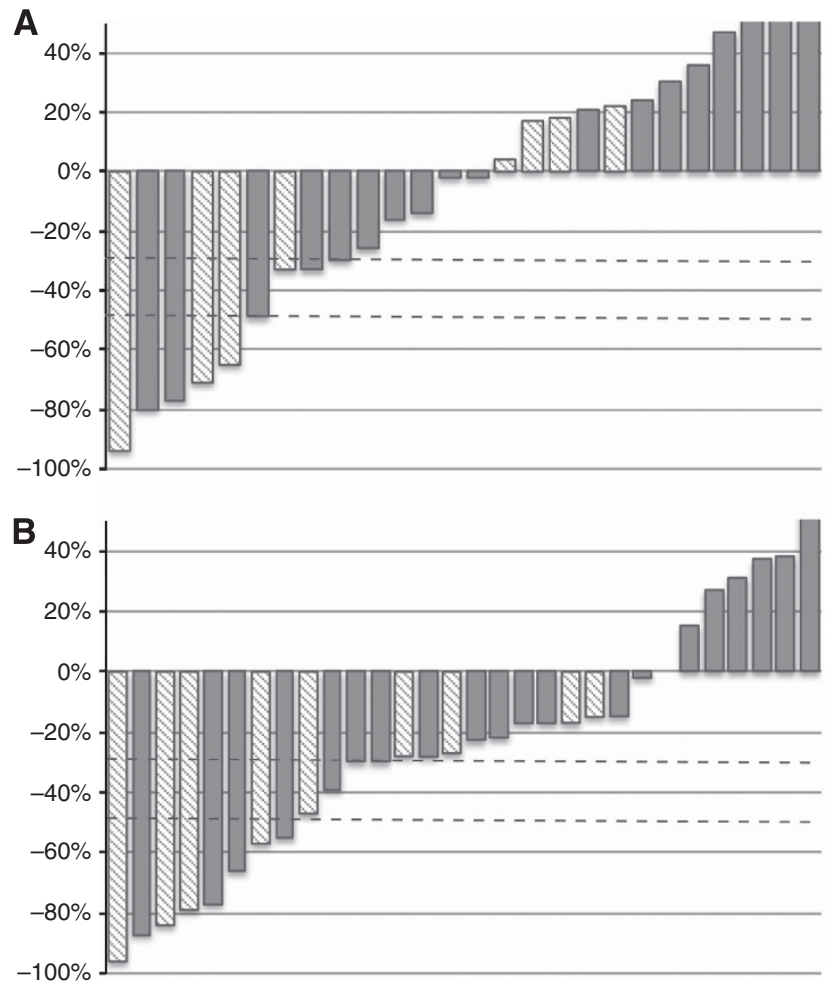

Prior single agent dexamethasone

No prior single agent dexamethasone

Figure 1. Waterfall graph representing PSA declines on steroid switch. (A) PSA declines at 12 weeks. (B) Maximum PSA declines. Striped bars represent patients with prior single agent dexamethasone; nonstriped bars represent patients with no prior single agent dexamethasone. PSA increases have been capped at $+50 \%$. switch to the first PSA value fulfilling progression criteria. Radiological responses were defined as per RECIST (Response Evaluation Criteria In Solid Tumours) version 1.1 (Eisenhauer et al, 2009).

Statistical analyses. Statistical analyses were performed with IBM SPSS Statistics version 20. Time on treatment with abiraterone and dexamethasone (after steroid switch), time to PSA progression and time to PSA nadir were calculated using the Kaplan-Meier method.

\section{RESULTS}

Patient characteristics. We performed a steroid switch on standard doses of abiraterone from prednisolone/prednisone $5 \mathrm{mg}$ twice daily to dexamethasone $0.5-1 \mathrm{mg}$ once daily at PSA progression in 30 patients. A total of 26 patients had a switch from $10 \mathrm{mg}$ prednisolone/prednisone to $0.5 \mathrm{mg}$ dexamethasone. One patient had an initial dose of $1.5 \mathrm{mg}$ once daily, which was successfully tapered to $0.5 \mathrm{mg}$ over the first 3 weeks. One patient received dexamethasone $2 \mathrm{mg}$ once daily initially, which was tapered to $1 \mathrm{mg}$ once daily over 3 weeks; the remaining two patients received dexamethasone $1 \mathrm{mg}$ once daily, with no dose modifications. Clinical characteristics of patients at the time of steroid switch are summarised in Table 1.

At the time of data cut-off, 23 patients had discontinued treatment and 7 patients still continued on treatment with abiraterone and dexamethasone. Treatments administered after discontinuation of abiraterone are summarised in Table 2.

Nine patients $(30 \%)$ had received previous single agent dexamethasone; all of these patients had documented disease progression on dexamethasone, which consisted in PSA progression in five patients and PSA and radiological progression in four patients. Patients had received abiraterone and prednisolone/ prednisone for a median of 27.73 weeks (range: 11.7-124.4) before replacing prednisolone/prednisone $5 \mathrm{mg}$ twice daily with dexamethasone $0.5-1 \mathrm{mg}$ once daily.

Duration of treatment. Treatment with abiraterone and dexamethasone was maintained for a median of 20.6 weeks

\section{Table 3. Clinical characteristics of patients with a confirmed $\geqslant 50 \%$ PSA decrease}

\begin{tabular}{|c|c|c|c|c|c|c|}
\hline Max. PSA decline (\%) & $95.6 \%$ & $84.5 \%$ & $79.4 \%$ & $78.6 \%$ & $77.2 \%$ & $57 \%$ \\
\hline Dose of daily Dex (mg) & 0.5 & 0.5 & 0.5 & 0.5 & $1^{a}$ & 0.5 \\
\hline \multicolumn{7}{|l|}{ Clinical characteristics at steroid switch } \\
\hline Age (years) & 73.1 & 81.8 & 61 & 62.5 & 63.6 & 73 \\
\hline ECOG PS on Switch & 1 & 0 & 1 & 1 & 0 & 0 \\
\hline $\mathrm{Hb}\left(\mathrm{g} \mathrm{dl}^{-1}\right)$ & 10 & 12.4 & 14.4 & 13.7 & 12.8 & 13.6 \\
\hline Alk Phos (IUI-1) & 2238 & 100 & 57 & 85 & NA & 53 \\
\hline $\mathrm{LDH}\left(\mathrm{IUI}^{-1}\right)$ & 418 & 214 & 171 & 169 & NA & 242 \\
\hline Albumin $\left(\mathrm{g} \mathrm{dl}^{-1}\right)$ & 36 & 42 & 37 & 34 & NA & 36 \\
\hline Metastases & Bone & Bone, LN & LN & Bone, LN & Bone & LN, Pulm \\
\hline \multicolumn{7}{|l|}{ Response to steroid switch } \\
\hline Baseline PSA before switch (ng ml ${ }^{-1}$ ) & 1084 & 2689 & 9.7 & 210 & 37.7 & 15 \\
\hline PSA nadir on switch & 48 & 418 & 1.9 & 45 & 8.5 & 6.5 \\
\hline Duration of treatment $\mathrm{Abi}+\mathrm{Dex}(\mathrm{m})$ & 12.2 (Ong) & 6.5 (Ong) & 5.7 & 13.9 & 5.5 (Ong) & 5.8 \\
\hline Time to PSA nadir on Abi + Dex (m) & 3.6 & 4.7 & 1.8 & 6.2 & 4.5 & 1.5 \\
\hline Time to PSA Progression on Abi + Dex (m) & 8.7 & 3.6 & 3.6 & 8.7 & 6.4 & 4.9 \\
\hline \multicolumn{7}{|l|}{ Treatment before switch } \\
\hline Duration of treatment AA + Pred $(\mathrm{m})$ & 4.8 & 4.8 & 22.1 & 14.9 & 6.7 & 6.4 \\
\hline Max. PSA decline on AA + Pred & $78 \%$ & $27 \%$ & $99 \%$ & $38 \%$ & $84 \%$ & $48 \%$ \\
\hline Previous single agent Dex (m) & Yes (59.9) & Yes (15.3) & No & Yes (3.5) & No & Yes (4.9) \\
\hline Time from previous single agent Dex $(m)$ & 28.1 & 15.6 & - & 45.8 & - & 6.4 \\
\hline Max. PSA decline on Previous single agent Dex & $97 \%$ & $27 \%$ & - & $38 \%$ & - & $71 \%$ \\
\hline Previous CT lines & 1 & 1 & 1 & 1 & 1 & 2 \\
\hline \multicolumn{7}{|c|}{ 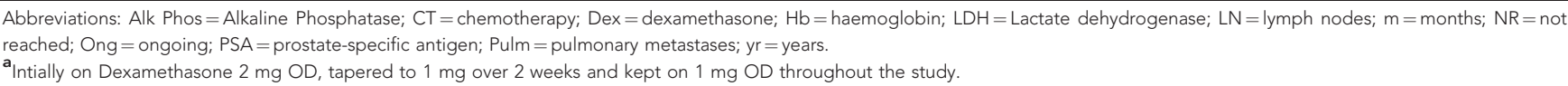 } \\
\hline
\end{tabular}



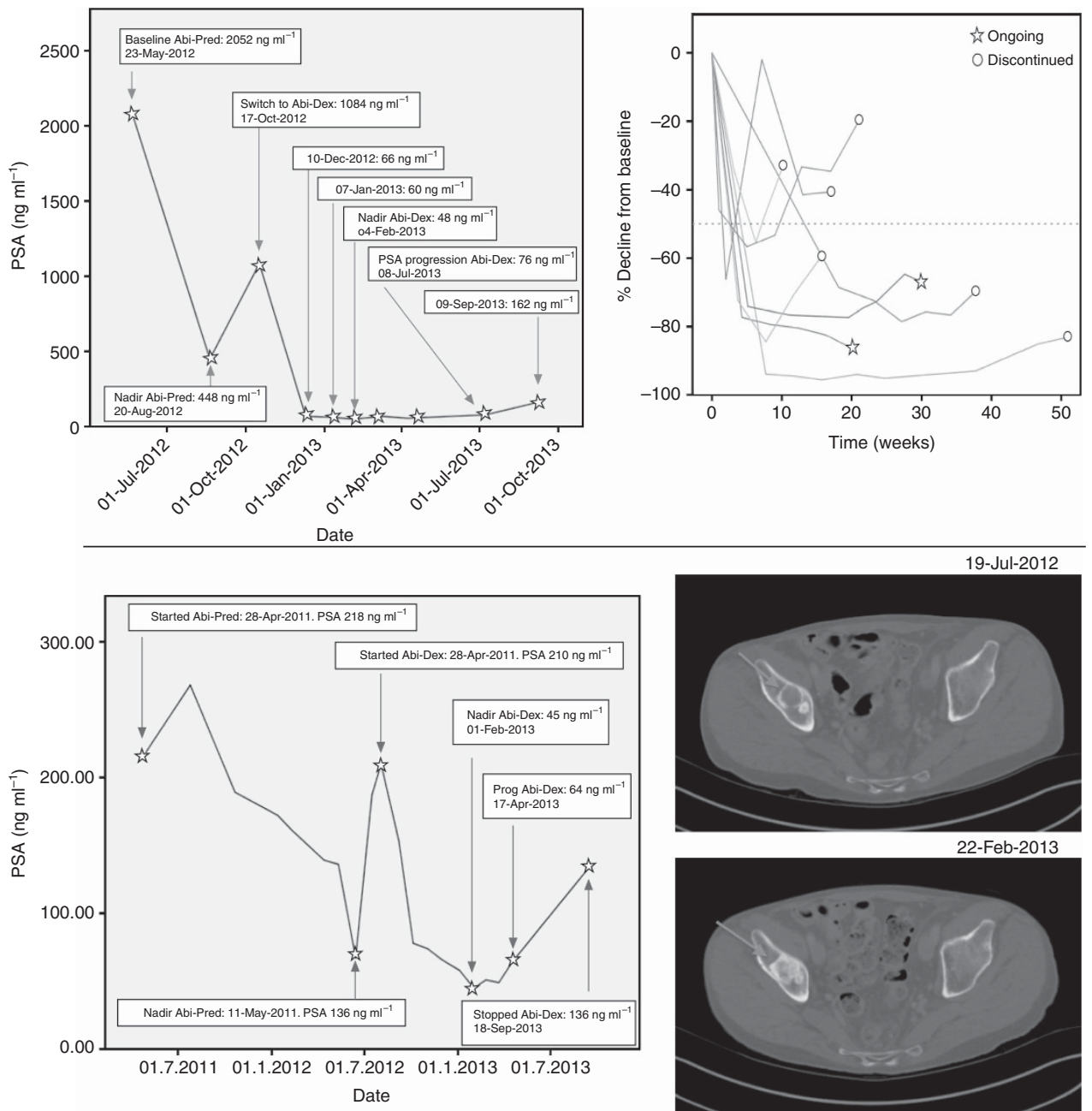

Sclerotic changes in bone metastases associated with a $77 \%$ PSA decline
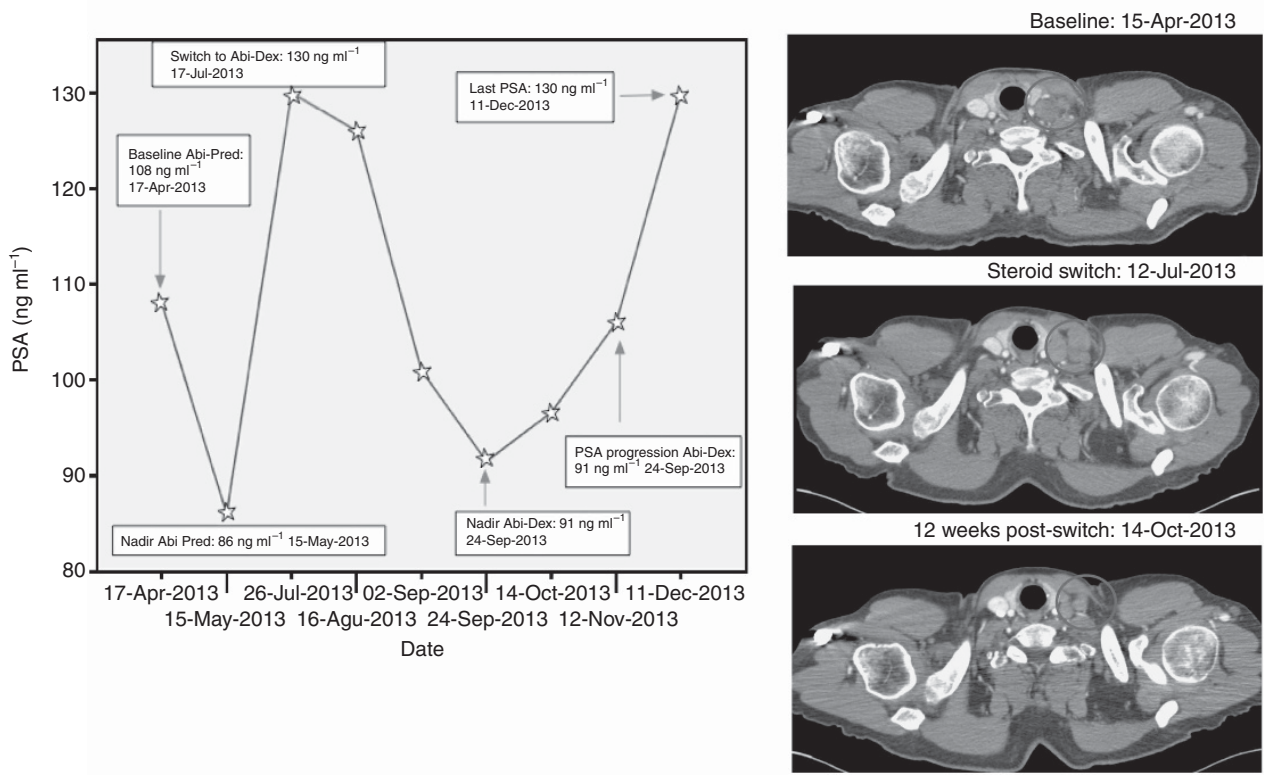

Figure 2. Top left: evolution of PSA values in a patient with a 95.6\% PSA decline. Top right: evolution of PSA values (\%) in patients with a $\geqslant 50 \%$ PSA decline. Middle: increased bone lesion sclerosis during treatment in a patient with a 77\% PSA decline. Bottom: RECIST PR in supraclavicular lymph nodes in a patient with a 30\% PSA decline.

(95\% CI: 16.2-24.9). A total of 23 patients had discontinued treatment and 7 patients continued on treatment at data censoring. Of these, 13 patients $(56.5 \%)$ discontinued treatment owing to radiological progression, 7 (30.4\%) owing to clinical progression and $3(13 \%)$ owing to PSA progression exclusively before being enroled in subsequent clinical trials. 
One patient stopped treatment because of radiological progression with new liver lesions on the CT scan performed owing to clinical worsening (increased fatigue and pain) 4 weeks after the steroid switch despite a 55\% decline in PSA levels. Upon discontinuation of abiraterone, this patient went on to receive cabazitaxel chemotherapy.

PSA declines. Declines in PSA $>50 \%$ that were confirmed by at least one PSA value 4 weeks later were observed in six patients. Two patients had unconfirmed maximal PSA declines of $66 \%$ and $55 \%$, respectively. PSA declines at 12 weeks and maximum PSA declines are represented in Figure 1. The clinical characteristics of the six patients with a confirmed PSA decline $\geqslant 50 \%$ are summarised in Table 3. Four of these patients remained on treatment at the time of data cut-off. Eleven patients $(39 \%)$ had confirmed PSA declines $\geqslant 30 \%$. Baseline PSA at steroid switch ranged from 9.7 to $2689 \mathrm{ng} \mathrm{ml}^{-1}$. Median time to PSA nadir in patients with a confirmed 50\% PSA decline was 7.7 weeks $(95 \% \mathrm{CI}$ : 0-20.8 weeks). Median time to PSA progression on abiraterone and dexamethasone was 11.7 weeks (95\% CI: 8.6-14.8 weeks) in the whole cohort and 27.6 weeks (95\% CI: 14.5-40.7 weeks) in patients who achieved a confirmed $50 \%$ PSA decline. The change in PSA values relative to baseline is represented in Figure 2. Three of seven patients with serum LDH above normal limits at steroid switch experienced a post-switch normalisation; all three patients had a $50 \%$ PSA decline.

Of the six patients with confirmed 50\% PSA declines, four had received previous treatment with single agent dexamethasone, for a duration ranging between 15.2 and 259.6 weeks. Five patients had received prior bicalutamide. Four patients had received prior docetaxel, one patient was chemotherapy naïve and one patient had received docetaxel and mitoxantrone. Response to previous treatment with abiraterone and prednisolone/prednisone ranged from a $27 \%$ to a $99 \%$ PSA decline.

Radiological response. Overall, 20 patients had a CT scan performed within 4 weeks before the steroid switch that was used as a baseline for response assessment. Nine patients had RECIST evaluable disease. One patient, with baseline bone metastasis and a histologically proven adrenal metastasis, showed a RECIST partial response after 12 weeks of treatment and a $77 \%$ confirmed PSA decline. A second RECIST partial response in supraclavicular and retroperitoneal nodes was observed after 12 weeks in a patient with baseline lymph node disease only in conjunction with a confirmed $30 \%$ PSA decline (Figure 2). Five patients with RECIST evaluable disease had stable disease on imaging assessment, with maximal PSA declines ranging from $80 \%$ to $15 \%$. Two of these patients showed no change in the size of the lymph nodes, but a significant increase in sclerosis of the bone lesions was observed (Figure 2).

Safety. Treatment was well tolerated with no grade 3 toxicities (see Table 4). No dose reductions of abiraterone were required. One patient, who was normotensive on abiraterone and prednisolone $5 \mathrm{mg}$ b.i.d. and had not been on antihypertensives, experienced grade 2 postural hypotension after steroid switch that mandated re-initiation of prednisolone $5 \mathrm{mg}$ b.i.d. before final discontinuation of abiraterone. Postural hypotension resolved after restarting prednisolone $5 \mathrm{mg}$ twice daily instead of dexamethasone $0.5 \mathrm{mg}$ once daily. Conversely, grade 1 and grade 2 hypertension was present in six patients (21\%), four of whom had also had hypertension of an equal grade on abiraterone and prednisolone $5 \mathrm{mg}$ twice daily that persisted despite institution of antihypertensive medication. Two patients (7.1\%) presented with grade 1 hypokalaemia, one of whom had also previously suffered two episodes of grade 1 hypokalaemia on abiraterone and prednisolone $5 \mathrm{mg}$ twice daily. Two patients $(7.1 \%)$ presented with self-limiting grade 1 to grade 2 transaminase elevation that resolved after 4 weeks. One patient experienced grade 1 hyponatraemia that lasted
Table 4. Toxicity before and after steroid switch

\begin{tabular}{|l|c|c|}
\hline Grade 1-2 Toxicity & Pre-switch & Post-switch \\
\hline Hypertension & $11(39.3 \%)$ & $7(29 \%)$ \\
\hline Hypokalaemia & $8(28.6 \%)$ & $2(7.1 \%)$ \\
\hline Transaminase elevation & $2(7.1 \%)$ & $1(3.6 \%)$ \\
\hline Other $^{\text {a }}$ & $1(3.6 \%)$ & $2(7.1 \%)$ \\
\hline $\begin{array}{l}\text { a Other: One patient experienced grade } 1 \text { hyponatraemia that lasted for } 4 \text { cycles while on } \\
\text { abiraterone + prednisolone, which reappeared after steroid switch for } 1 \text { cycle and was } \\
\text { spontaneously recovered. One patient experienced grade } 2 \text { postural hypotension after } \\
\text { steroid switch. }\end{array}$ \\
\hline
\end{tabular}

for four cycles while on abiraterone and prednisolone, and persisted for two cycles after steroid switch. No new episodes of fluid retention or other adverse events were observed.

\section{DISCUSSION}

This is the first report of multiple durable PSA declines in patients treated with abiraterone after a steroid switch from prednisolone $5 \mathrm{mg}$ b.i.d. to dexamethasone $0.5-1 \mathrm{mg}$ once daily. In seven patients, maximum PSA declines on abiraterone and dexamethasone were at least $25 \%<$ those achieved on abiraterone and prednisolone, and eight patients had a longer treatment duration on abiraterone and dexamethasone than on abiraterone and prednisolone (Figure 1). This hypothesis-generating report should now lead to prospective evaluation of changes in steroid dose while continuing and after discontinuing abiraterone.

Radiological responses in soft tissue and/or nodal disease were observed in two out of nine patients. Increased sclerosis on CT with no change in the size of bone metastases was also observed in three patients who also had PSA declines. There are currently no established objective criteria to evaluate response in bone metastatic disease on CT scans; preliminary data suggest that an increase in bone lesion sclerosis may be associated with therapeutic response, as suggested by the correlation between reduction in FDG uptake and increased CT density (measured in Hounsfield units) of bone metastases from prostate cancer (Beheshti et al, 2008; Costelloe et al, 2010).

Conversion to dexamethasone was well tolerated and was not associated with adrenocortical insufficiency or side effects of mineralocorticoid excess. Dexamethasone has been reported to cause orthostatic hypotension when given as a treatment of secondary mineralocorticoid excess in a phase I trial of abiraterone without concomitant steroids (Ryan et al, 2010). A currently ongoing phase II clinical trial (NCT01867710) is evaluating the safety profile of abiraterone given with different steroid regimens (prednisolone $5 \mathrm{mg}$ twice daily, prednisolone $2.5 \mathrm{mg}$ twice daily, prednisolone $5 \mathrm{mg}$ once daily and dexamethasone $0.5 \mathrm{mg}$ once daily) to chemotherapy-naïve metastatic CRPC patients. Moreover, abiraterone activity could be enhanced if combined with eplerenone instead of prednisolone, which, as previously reported, is feasible (Attard et al, 2008, 2009).

Several hypotheses could be considered to explain the observed effect. Possible mechanisms of resistance that would be reversed by 'steroid switch' are as follows:

(1) Activation of the glucocorticoid receptor leads to resistance, as recently published for enzalutamide (Arora et al, 2013), which is reversed owing to the lower equivalent dose of dexamethasone compared with prednisolone. Reduced activation of the glucocorticoid receptor by doses of dexamethasone with a lower equivalent glucocorticoid activity induces less activation of the GR. In all, $90 \%$ of the patients in our study ultimately received $0.5 \mathrm{mg}$ dexamethasone daily, which represents a $67 \%$ reduction in glucocorticoid activity compared with 
prednisolone $5 \mathrm{mg}$ twice daily. The remaining three patients (10\%) received a dose of dexamethasone $1 \mathrm{mg}$ once daily, representing a 33\% reduction in glucocorticoid activity; only one of the patients receiving dexamethasone $1 \mathrm{mg}$ once daily achieved a $>50 \%$ PSA decline.

(2) Resistance occurs secondary to emergence of AR somatic point mutations that are activated by prednisolone but not by dexamethasone.

(3) Resistance occurs secondary to activation of the mineralocorticoid receptor, for which dexamethasone has a lower affinity (Lan et al, 1982).

(4) Other factors that may also contribute to the superior activity of dexamethasone in CRPC, including when administered as a single agent.

We acknowledge the lack of a control group in which abiraterone was discontinued at the time of steroid switch as a major limitation of the study. The possibility of the observed responses being related to the activity of dexamethasone as a single agent can therefore not be excluded. However, the similar response rate in patients regardless of progression on prior single agent dexamethasone suggests that an alternative mechanism is responsible for the observed responses.

In conclusion, performing a steroid switch in patients with a rising PSA while on abiraterone can delay the development of resistance, and it can induce radiological responses in selected patients. Prospective clinical trials with integrated biomarker studies are now required to further evaluate the extent of benefit and the biological mechanisms underlying our observations.

\section{ACKNOWLEDGEMENTS}

D Lorente is recipient of a 2-year bursary from the Spanish Society of Medical Oncology - 'Beca SEOM Para la Investigación Traslacional en el Extranjero'. A Omlin is the recipient of a 2 -year bursary from the Swiss Cancer League (No. BIL KLS02592-02-2010). R Ferraldeschi is supported by the Wellcome Trust. Z Zafeirou is the recipient of a grant from the Hellenic Society of Medical Oncology. G Attard is supported by a Cancer Research UK Clinician Scientist Fellowship. G Attard and J de Bono have received support from Prostate Cancer UK and the Prostate Cancer Foundation.

\section{REFERENCES}

Arora V, Schenkein E, Murali R, Subudhi SK, Wongvipat J, Balbas MD, Shah N, Cai L, Efstathiou E, Logothetis C, Zhend D, Sawyers CL (2013) Glucocorticoid receptor confers resistance to antiandrogens by bypassing androgen receptor blockade. Cell 155(6): 1309-1322.

Attard G, Reid AH, A'Hern R, Parker C, Oommen NB, Folkerd E, Messiou C, Molife LR, Maier G, Thompson E, Olmos D, Sinha R, Lee G, Dowsett M Kaye SB, Dearnaley D, Kheoh T, Molina A, de Bono JS (2009) Selective inhibition of CYP17 with abiraterone acetate is highly active in the treatment of castration-resistant prostate cancer. J Clin Oncol 27(23): 3742-3748.
Attard G, Reid AH, Yap TA, Raynaud F, Dowsett M, Settatree S, Barrett M, Parker C, Martins V, Folkerd E, Clark J, Cooper CS, Kaye SB, Dearnaley D, Lee G, de Bono JS (2008) Phase i clinical trial of a selective inhibitor of CYP17, abiraterone acetate, confirms that castration-resistant prostate cancer commonly remains hormone driven. J Clinical Oncology: Official Journal of the American Society of Clinical Oncology 26(28): 4563-4571.

Beheshti M, Vali R, Waldenberger P, Fitz F, Nader M, Loidl W, Broinger G, Stoiber F, Foglman I, Langsteger W (2008) Detection of bone metastases in patients with prostate cancer by $18 \mathrm{~F}$ fluorocholine and $18 \mathrm{~F}$ fluoride PET-CT: a comparative study. Eur J Nucl Med Mol Imaging 35(10): 1766-1774.

Costelloe CM, Chuang HH, Madewell JE, Ueno NT (2010) Cancer response criteria and bone metastases: RECIST 1.1, MDA and PERCIST. J Cancer 1: 80-92.

de Bono JS, Logothetis CJ, Molina A, Fizazi K, North S, Chu L, Chi KN, Jones RJ, Goodman Jr OB, Saad F, Staffurth JN, Mainwaring P, Harland S, Flaig TW, Hutson TE, Cheng T, Patterson H, Hainsworth JD, Ryan CJ, Sternberg CN, Ellard SL, Fléchon A, Saleh M, Scholz M, Efstathiou E, Zivi A, Bianchini D, Loriot Y, Chieffo N, Kheoh T, Haqq CM, Scher HI. COU-AA-301 Investigators (2011) Abiraterone and increased survival in metastatic prostate cancer. New Engl J Med 364(21): 1995-2005.

Eisenhauer EA, Therasse P, Bogaerts J, Schwartz LH, Sargent D, Ford R, Dancey J, Arbuck S, Gwyther S, Mooney M, Rubinstein L, Shankar L, Dodd L, Kaplan R, Lacombe D, Verweij J (2009) New response evaluation criteria in solid tumours: revised RECIST guideline (version 1.1). Eur J Cancer 45(2): 228-247.

Lan NC, Graham B, Bartter FC, Baxter JD (1982) Binding of steroids to mineralocorticoid receptors: implications for in vivo occupancy by glucocorticoids. J Clin Endocrinol Met 54(2): 332-342.

Ryan CJ, Smith MR, Fong L, Rosenberg JE, Kantoff P, Raynaud F, Martins V, Lee G, Kheoh T, Kim J, Molina A, Small EJ (2010) Phase I clinical trial of the CYP17 inhibitor abiraterone acetate demonstrating clinical activity in patients with castration-resistant prostate cancer who received prior ketoconazole therapy. J Clin Oncol 28(9): 1481-1488.

Scher HI, Fizazi K, Saad F, Taplin ME, Sternberg CN, Miller K, de Wit R, Mulders P, Chi KN, Shore ND, Armstrong AJ, Flaig TW, Fléchon A, Mainwaring P, Fleming M, Hainsworth JD, Hirmand M, Selby B, Seely L, de Bono JS. AFFIRM Investigators (2012) Increased survival with enzalutamide in prostate cancer after chemotherapy. New Engl J Med 367(13): 1187-1197.

Scher HI, Halabi S, Tannock I, Morris M, Sternberg CN, Carducci MA, Eisenberger MA, Higano C, Bubley GJ, Dreicer R, Petrylak D, Kantoff P, Basch E, Kelly WK, Figg WD, Small EJ, Beer TM, Wilding G, Martin A, Hussain M. Prostate Cancer Clinical Trials Working Group (2008) Design and end points of clinical trials for patients with progressive prostate cancer and castrate levels of testosterone: recommendations of the prostate cancer clinical trials working group. J Clin Oncol 26(7): 1148-1159.

Venkitaraman Ramachandran, Thomas Karen, Murthy Vedang, Woode-Amissah Ruth, Dearnaley David Paul, Horwich Alan, Huddart Robert Anthony, De Bono Johann Sebastian, Parker Chris (2013) A randomized phase II trial of dexamethasone versus prednisolone as secondary hormonal therapy in CRPC. ASCO Meeting Abstracts 31(6_suppl): 123 .

This work is published under the standard license to publish agreement. After 12 months the work will become freely available and the license terms will switch to a Creative Commons AttributionNonCommercial-Share Alike 3.0 Unported License. 